\title{
Gene amplification and protein overexpression of MET are common events in ovarian clear-cell adenocarcinoma: their roles in tumor progression and prognostication of the patient
}

\author{
Sohei Yamamoto ${ }^{1}$, Hitoshi Tsuda ${ }^{2}$, Kosuke Miyai ${ }^{1}$, Masashi Takano ${ }^{3}$, Seiichi Tamai ${ }^{4}$ and \\ Osamu Matsubara ${ }^{1}$ \\ ${ }^{1}$ Department of Basic Pathology, National Defense Medical College, Saitama, Japan; ${ }^{2}$ Pathology and Clinical \\ Laboratory Division, National Cancer Center Hospital, Chuo-ku, Tokyo, Japan; ${ }^{3}$ Department of Obstetrics and \\ Gynecology, National Defense Medical College, Saitama, Japan and ${ }^{4}$ Department of Clinical Laboratory, \\ National Defense Medical College Hospital, Tokorozawa, Saitama, Japan
}

\begin{abstract}
The aim of this study was to assess protein overexpression and gene copy number alterations of MET in ovarian clear-cell adenocarcinoma, and to assess its potential as a novel therapeutic target. Ninety cases of clear-cell adenocarcinoma were analyzed for MET protein overexpression and copy number alterations of the MET gene by immunohistochemistry and brightfield double in situ hybridization, respectively. In addition, 101 cases of the non-clear-cell type ovarian carcinomas at advanced stages were also evaluated for comparison. MET overexpression was assigned when complete membrane staining with moderate or strong intensity was observed in at least $10 \%$ of the tumor cells examined. Double in situ hybridization was determined as positive when the tumor exhibited high-level polysomy ( $\geq 4$ copies in $\geq 40 \%$ of tumor cells) or MET gene amplification. MET overexpression was detected in 20 of 90 clear-cell adenocarcinomas (22\%) and none of 111 non-clear-cell type ovarian carcinomas. Double in situ hybridization was positive in 21 of 89 informative clear-cell adenocarcinomas (24\%) and only 3 non-clear-cell type ovarian carcinomas (3\%). In the whole population, true amplification of the MET gene was detected only in the clear-cell adenocarcinoma histology (five cases, $6 \%$ ). In clear-cell adenocarcinomas, double in situ hybridization positivity was highly correlated with the presence of MET overexpression and a poorly differentiated histology of tumors $(P=0.0105$ and 0.00038 , respectively). For the patients with clear-cell adenocarcinomas, MET overexpression, as well as advanced clinical stage and the poorly differentiated histology of tumors, was identified as an independent unfavorable prognostic factor for overall survival. In conclusion, among ovarian carcinomas, the amplification of the MET proto-oncogene is highly selective and commonly occurs in clear-cell adenocarcinoma. MET could serve as a biomarker for the prognostication of patients with clear-cell adenocarcinoma and tumor progression, and has potential as a novel therapeutic target for this carcinoma.
\end{abstract}

Modern Pathology (2011) 24, 1146-1155; doi:10.1038/modpathol.2011.70; published online 8 April 2011

Keywords: clear-cell adenocarcinoma; c-Met; gene amplification; in situ hybridization; MET; ovarian cancer; prognostic factor

Correspondence: Dr H Tsuda, MD, Pathology and Clinical Laboratory Division, National Cancer Center Hospital, 5-1-1 Tsukiji, Chuo-ku, Tokyo 104-0045, Japan.

E-mail: hstsuda@ncc.go.jp

Received 21 November 2010; revised 17 February 2011; accepted 17 February 2011; published online 8 April 2011
Clear-cell adenocarcinoma accounts for $5-10 \%$ of all epithelial ovarian cancers in Western countries, whereas in Japan, for unknown reasons, it accounts for $>20 \%{ }^{1-3}$ Among the ovarian carcinomas, clearcell adenocarcinoma has been recognized as a form of lethal histological subtype, mainly resulting from its highly chemoresistant nature. ${ }^{1-7}$ Surgical 
debulking of the tumor is thought to be the only effective treatment for improving the prognosis of clear-cell adenocarcinoma, and some studies have reported a poor prognosis for that carcinoma even when detected at an early stage. ${ }^{4-7}$ Despite progress in surgical techniques and modalities of chemotherapy for ovarian cancer, the mortality rate of patients with clear-cell adenocarcinoma has remained largely unchanged. Hence, there is a need to improve our understanding of its pathobiology in order to develop new therapeutic strategies and optimize currently available treatments.

A unique member of the receptor tyrosine kinase family, MET, has attracted much attention in recent years, representing an intriguing target for cancer therapy, although that has not yet been established in a clinical setting. MET, located on chromosome 7q31, encodes some functional domains, including the ligand-binding domain, regulatory juxtamembrane domain, and the receptor tyrosine kinase domain. ${ }^{8}$ Physiologically, on binding of its ligand, hepatocyte growth factor (HGF, also known as scatter factor), the MET receptor, undergoes dimerization and autophosphorylation at specific tyrosine residues within the cytoplasmic domain, creating docking sites for intracellular signal transducers that activate the Ras-mitogen-activated protein kinase, the phosphatidylinositol 3-kinase (PI3K), and the signal transducers and activators of transcription signaling pathways. ${ }^{8,9}$

The overexpression of MET has been reported in several epithelial and mesenchymal cancers, and in general, a high expression level of MET is associated with cancer progression and an adverse outcome for these patients. ${ }^{8,9}$ In contrast to non-neoplastic cells, MET in tumor cells can be activated in a ligandindependent manner through activating mutation, amplification, and overexpression of the MET gene. ${ }^{8-10}$ However, to date, it is thought that somatic mutation of the MET gene is quite a rare event in sporadic primary carcinomas of adults, including ovarian carcinomas, ${ }^{11,12}$ with papillary carcinoma of the kidney being the exception. ${ }^{13}$ On the other hand, $M E T$ gene amplification was identified in 5-10\% of gastric cancers, ${ }^{14-16} 4 \%$ of esophageal cancers, ${ }^{17}$ $3-4 \%$ of lung cancers, ${ }^{18,19}$ and $10 \%$ of colorectal cancers. ${ }^{20}$

The MET receptor is found to be expressed in approximately $70 \%$ of human ovarian carcinomas, and overexpressed in $30 \%$ of cases and cell lines; ${ }^{21-26}$ MET overexpression was reported to be correlated with adverse outcomes for the patients. ${ }^{24,25}$ Blocking the effects of HGF by neutralizing antibodies, the HGF antagonist, or knocking out MET expression by small interfering RNA has been shown to inhibit peritoneal dissemination and ascites formation of ovarian cancer cells in vivo. ${ }^{26}$ However, only a small number of cases with clearcell adenocarcinoma were enrolled in those studies, and little is known about the status of copy number alterations of $M E T$ in ovarian carcinomas.
In the present study, using immunohistochemistry and brightfield double in situ hybridization, we sought first to determine the frequencies of MET protein overexpression and copy number alterations of the $M E T$ gene in ovarian carcinomas, especially focusing on clear-cell adenocarcinoma; second, to clarify the relationship between that protein overexpression and gene copy number alterations; and third, to examine the clinicopathological significance of MET overexpression and its altered gene copy number in the patients with clear-cell adenocarcinoma. This information will not only lead to better understanding of the pathobiology of ovarian clear-cell adenocarcinoma, but also provide insight into potential treatment options for this highly lethal malignancy.

\section{Materials and methods}

\section{Patients and Tissue Samples}

Primary ovarian carcinomas-201 cases as a consecutive series, including 90 clear-cell adenocarcinomas and 111 non-clear-cell type ovarian carcinomas-were identified from the files of the Department of Clinical Laboratory, National Defense Medical College Hospital, Japan. These 201 patients underwent surgical resection between 1987 and 2007 , and none had undergone chemotherapy or radiation therapy before surgery. All specimens were formalin fixed and paraffin embedded, and tumors were classified according to the criteria of the World Health Organization. ${ }^{4}$ For clear-cell adenocarcinoma cases, tumors at all clinical stages (stages I-IV) were included. For non-clear-cell type ovarian carcinoma cases, tumors at the advanced stages (stage III/IV) —as defined by the International Federation of Gynaecology and Obstetrics (FIGO) staging system-were selected, including 89 cases of serous adenocarcinoma, 12 of mucinous adenocarcinoma, and 10 endometrioid adenocarcinomas.

For the patients with clear-cell adenocarcinoma, clinicopathological details such as patient age, clinical stage of disease, residual tumor after initial cytoreductive surgery, clinical response to chemotherapy, regional lymph node status, histological grade of the tumor, and overall survival were assessed. These clinicopathological features are listed in Table 1. Of the 90 patients with clear-cell adenocarcinoma, $88(98 \%)$ received post-operative platinum-based chemotherapy after initial surgery. The chemotherapeutic regimens comprised irinotecan and cisplatin in 39 patients; cyclophosphamide, doxorubicin, and cisplatin in 30 patients; etoposide and cisplatin in 8 patients; paclitaxel and carboplatin in 5 patients; cyclophosphamide and cisplatin in 3 patients; irinotecan and carboplatin in 2 patients; and paclitaxel and cisplatin in 1 patient. A secondlook operation or second reductive surgery was performed, depending on the surgeon's preference. Clinical response to chemotherapy was assessed for 
Table 1 Clinical characteristics of the patients with ovarian clear-cell adenocarcinoma enrolled

\begin{tabular}{lc}
\hline Characteristics & Number of cases (\%) \\
\hline Age (years); median (s.d.) & $52.9(8.1)$ \\
& \\
FIGO stage & $49(54)$ \\
I & $9(10)$ \\
II & $27(30)$ \\
III & $5(6)$ \\
IV & \\
Residual tumor after initial surgery & $63(70)$ \\
Absent & $27(30)$ \\
Present & \\
Response to first-line chemotherapies & $10(37)$ \\
Complete response or & $17(63)$ \\
Partial response & \\
Stable disease or & \\
Progressive disease & \\
Lymph node status & $46(79)$ \\
pNo & \\
pN1 & \\
pNx (not assessable) & 32 \\
Poorly differentiated histology in clear-cell adenocarcinoma \\
Absent \\
Present & $68(76)$ \\
\hline
\end{tabular}

FIGO, International Federation of Gynaecology and Obstetrics.

a pN0, no lymph node metastases; pN1, one or more lymph node metastasis found in pelvic or paraaortic lymph nodes.

the 27 patients with a measurable residual tumor (regardless of size) after initial surgery, evaluated by ultrasonography or computed tomography, and classified into complete response, partial response, stable disease, or progressive disease according to the new Response Evaluation Criteria for Solid Tumours guidelines. ${ }^{27}$ Follow-up was calculated from the date of initial definitive surgery to the date of either last follow-up or death. The average followup period after initial surgery was 52.0 months, ranging between 2 and 182 months. Thirty (33\%) of 90 patients died because of their tumor burden, and 1 patient died because of another cause.

The research protocol was approved by the ethics committee of the National Defense Medical College, Tokorozawa, Japan.

\section{Poorly Differentiated Histology in Clear-Cell Adenocarcinoma}

To assess the relationship between altered expression of MET and histological progression/dedifferentiation of clear-cell adenocarcinoma, we have set criteria for the poorly differentiated histology of that carcinoma. Since clear-cell adenocarcinoma is a subtype of adenocarcinoma, the following architectures were defined as poorly differentiated histology of that carcinoma: tumor cells growing as solid masses, cords, or individual tumor cells infiltrating toward surrounding stromal tissue, without easily discernible glandular differentiation. Small foci may show gland formation, but there should be one gland or less in a low-power field of view $\left(5.51 \mathrm{~mm}^{2}\right.$ using $\times 10$ objective lens). When these poorly differentiated components occupying $5.51 \mathrm{~mm}^{2}$ or more, the component was judged as present. The solid appearance of glands growing in a cribriform or fusiform papillary pattern, where the latter contain easily discernible fibrovascular cores of papillae in solid growth, was not considered a poorly differentiated component.

\section{Construction of Tissue Microarray}

To construct tissue microarray blocks, we selected formalin-fixed paraffin-embedded cancer tissue blocks from all 90 clear-cell adenocarcinoma cases and all 111 non-clear-cell type ovarian carcinomas. Two core specimens, $2.0 \mathrm{~mm}$ in diameter, for each case were taken from these blocks and transferred to recipient blocks using a Tissue Microarrayer (Beecher Instrument, Silver Spring, MD, USA). For the cases with clear-cell adenocarcinoma, if the tumor area contained foci of poorly differentiated histological components, at least 1 core was punched out from these components. These tissue microarray blocks were then cut into 4-ím-thick sections and subjected to both immunohistochemistry and brightfield double in situ hybridization analyses.

\section{Immunohistochemistry}

Sections were subjected to a BenchMark ${ }^{\circledR}$ XT automated slide processing system (Ventana Medical Systems, Tucson, Arizona). The primary antibody used was a rabbit monoclonal antibody against the carboxyl region of the transmembrane human c-Met (MET) protein (CONFIRM anti-Total c-MET (SP44), ready for use; Ventana). The immunoreaction was visualized by using an ultraView DAB Detection kit (Ventana) according to the manufacturer's instructions. ${ }^{28}$ Endothelial cells in the tumor tissues served as positive controls for the antibody examined. Sections without the primary antibody were used as negative controls.

\section{Brightfield Double In Situ Hybridization}

The BenchMark ${ }^{\circledR}$ XT automated slide processing system was used for the optimization of the double in situ hybridization assay for copy number alteration of the MET gene. A detailed protocol of these methods was described by Nitta et al. ${ }^{28}$ Briefly, deparaffinized tissue sections were pretreated with a combination of heat treatment with reaction buffer (Tris-based pH 7.6 solution; Ventana) and ISH Protease 3 (Ventana) to unmask DNA targets. For the MET gene detection, the INFORM ${ }^{\mathbb{R}}$ MET DNA Probe (Ventana), a dinitrophenyl (DNP)-labeled probe, was applied to the tissue sections, denatured 
at $95^{\circ} \mathrm{C}$ and hybridized at $52^{\circ} \mathrm{C}$ for $6 \mathrm{~h}$. After wash steps with $2 \times$ SCC (Ventana), tissue sections were incubated with monoclonal rabbit anti-DNP antibody (Ventana) for $20 \mathrm{~min}$ and then with HRPconjugated goat anti-rabbit antibody for $16 \mathrm{~min}$ at $37^{\circ} \mathrm{C}$. The metallic silver deposit for MET ISH signal was developed using the ultraView ${ }^{\mathrm{TM}}$ SISH Detection kit (Ventana). For CEN 7 detection, the INFORM Chromosome 7 Probe (Ventana), a DNP-labeled oligoprobe, was applied to the tissue sections, denatured at $95^{\circ} \mathrm{C}$, and hybridized at $44^{\circ} \mathrm{C}$ for $2 \mathrm{~h}$. Then, after wash steps with $2 \times$ SSC, tissues were incubated with monoclonal rabbit anti-DNP antibody for $20 \mathrm{~min}$ and then with an alkaline phosphatase (AP)-conjugated goat anti-rabbit antibody for $12 \mathrm{~min}$ at $37^{\circ} \mathrm{C}$. The signal for CEN 7 was visualized with a fast red and naphthol phosphate reaction using an ultraView Red ISH Detection kit. Finally, counterstain with hematoxylin was performed.

\section{Interpretation of the Immunohistochemistry and Double In Situ Hybridization Data}

The data of immunohistochemistry and double in situ hybridization were evaluated independently by two observers (SY and KM). In the interpretation of immunohistochemistry, any discrepancies between the two observers were resolved by discussion, and using a multiviewer microscope.

The intensity of the immunoreaction was scored using a four-tier system with the same criteria as used for assessing HER2/neu immunoreaction in breast cancer (the HercepTest ${ }^{\mathrm{TM}}$ criteria): $^{29}$ negative, no discernible staining or background type staining; $1+$, definite cytoplasmic staining and/or equivocal discontinuous membrane staining; $2+$, unequivocal membrane staining with mild to moderate intensity; $3+$, strong and complete membrane staining. MET overexpression was defined as moderate $(2+)$ or strong $(3+)$ when complete membrane staining was observed in at least $10 \%$ of the tumor cells. For each individual case, the extent (\%) of overexpressing cells was determined in a percentage of immunoreactive tumor cells on the tissue microarray cores from each case.

For double in situ hybridization analysis, the number of dark brown and red dot signals, corresponding to the copies of the MET gene and those of CEN 7, respectively, were counted in 80 interphase tumor cell nuclei (40 cells by 1 observer) using a $\times 100$ oil immersion objective lens. When the tentative averages of counted gene copy numbers per nucleus in a tumor significantly differed between the observers, the two observers counted a further 80 nuclei. All cases were arranged in four categories as follows: disomy $(\leq 2 M E T$ copies in $>90 \%$ of cells), low genomic gain ( $\geq 3 \mathrm{MET}$ copies in $\geq 10 \%$ of cells and $\geq 4$ copies of the $M E T$ gene in $<40 \%$ of cells), high-level polysomy ( $\geq 4$ copies of the $M E T$ gene in $\geq 40 \%$ of cells), or gene amplification (presence of tight gene clusters, a ratio $M E T$ gene/CEN7 per cell $\geq 2$, or $\geq 15$ copies of the $M E T$ gene in $\geq 10 \%$ of cells examined) using the reported criteria. $^{30}$ Then, the two former and the two latter

Table 2 MET overexpression and copy number alterations in ovarian clear-cell adenocarcinomas and non-clear-cell type ovarian carcinomas

\begin{tabular}{|c|c|c|c|c|c|c|}
\hline \multirow[t]{3}{*}{ Histological types } & \multirow{3}{*}{ Total } & \multicolumn{4}{|c|}{ Number of tumors (\%) } & \multirow[t]{3}{*}{ P-value } \\
\hline & & \multirow[t]{2}{*}{ Negative } & \multicolumn{3}{|c|}{ Overexpression } & \\
\hline & & & $1+$ & $2+$ & $3+$ & \\
\hline \multicolumn{7}{|c|}{ (a) MET immunoreaction } \\
\hline Clear cell & 90 & $31(34)$ & $39(43)$ & $17(19)$ & $3(3)$ & $<0.00001^{\mathrm{a}}$ \\
\hline Non-clear cell & 111 & 88 (79) & $23(21)$ & 0 & 0 & \\
\hline Serous & 89 & $75(84)$ & $14(16)$ & 0 & 0 & \\
\hline Mucinous & 12 & $6(50)$ & $6(50)$ & 0 & 0 & \\
\hline Endometrioid & 10 & $7(70)$ & $3(30)$ & 0 & 0 & \\
\hline \multirow[t]{3}{*}{ Histological types } & & \multicolumn{4}{|c|}{ Number of tumors (\%) } & P-value \\
\hline & \multirow[t]{2}{*}{ Total $^{\mathrm{b}}$} & \multicolumn{2}{|c|}{ Negative } & \multicolumn{2}{|c|}{ Positive } & \\
\hline & & Disomy & Low gain & High polysomy & Amplification & \\
\hline \multicolumn{7}{|c|}{ (b) Copy number alterations by double in situ hybridization } \\
\hline Clear cell & 89 & $20(22)$ & $48(54)$ & $16(18)$ & $5(6)$ & $<0.0001^{\mathrm{a}}$ \\
\hline Non-clear cell & 106 & $47(44)$ & $56(53)$ & $3(3)$ & 0 & \\
\hline Serous & 86 & $35(41)$ & $48(56)$ & $3(3)$ & 0 & \\
\hline Mucinous & 11 & $7(64)$ & $4(36)$ & 0 & 0 & \\
\hline Endometrioid & 9 & $5(56)$ & $4(44)$ & 0 & 0 & \\
\hline
\end{tabular}

${ }^{\mathrm{a} C}$ Comparison between clear-cell adenocarcinomas and non-clear-cell carcinomas.

${ }^{\mathrm{b}}$ Number of informative cases for double in situ hybridization analysis. 
were classified as double in situ hybridization negative and double in situ hybridization positive, respectively.

\section{Statistical Analysis}

Statistical analyses were performed using StatMate III software (ATMS, Tokyo, Japan). Comparisons between parameters were computed by the $\chi^{2}$ test. For survival analysis, Kaplan-Meier curves were drawn and differences between the curves were calculated by the log-rank test. Independent prognostic significance was computed by the Cox proportional hazards general linear model. Differences at $P<0.05$ were considered to be statistically significant.

\section{Results}

Frequent Protein Overexpression and Copy Number Alterations of the MET Gene in Clear-Cell Adenocarcinomas, Compared with Non-Clear-Cell Type Ovarian Carcinomas

MET immunoreaction was detected $(\geq 1+)$ in 59 out of 90 clear-cell adenocarcinomas $(66 \%)$ and 23 out of 111 non-clear-cell type ovarian carcinomas (21\%), respectively (Table 2a). MET overexpression $(\geq 2+)$ was assigned in 20 out of 90 clear-cell adenocarcinomas $(22 \%)$ and none of 111 non-clear-cell type ovarian carcinomas (Figure 1). In the former, 17 and 3 cases were scored as $2+$ and $3+$, respectively. Consequently, when compared with non-clear-cell type ovarian carcinomas, the frequency of both MET immunoreaction $(\geq 1+)$ and MET overexpression $(\geq 2+)$ was significantly higher in the clear-cell adenocarcinoma $(P<0.00001$, respectively).

Results of double in situ hybridization analysis for copy number alteration of the MET gene in clear-cell adenocarcinomas and non-clear-cell type ovarian carcinomas were summarized in Table $2 \mathrm{~b}$. Information about the copy number alteration of the MET gene and CEN7 was obtained from $89(99 \%)$ of 90 clear-cell adenocarcinomas and 106 (95\%) of 111 non-clear-cell type ovarian carcinomas. In one clearcell adenocarcinoma and five non-clear-cell type ovarian carcinomas, double in situ hybridization was performed, but dot signals were not visible, or cells with countable signals were $<40$ in the tissue microarray cores even though the assays were repeated. In the informative cases, 20 out of 89 clear-cell adenocarcinomas (22\%) and 47 out of 106 non-clear-cell type ovarian carcinomas (44\%) were considered as disomy (Figure 2a). Low genomic gain of the $M E T$ gene (Figure $2 \mathrm{~b}$ ) was detected in 48 clearcell adenocarcinomas (54\%) and in 56 non-clear-cell type ovarian carcinomas (53\%); the latter included 48,4 , and 4 cases with serous (56\%), mucinous $(36 \%)$, and endometrioid (44\%) adenocarcinomas, respectively. A high-level polysomy (Figure 2c) was


Figure 1 Representative immunohistochemistry for MET. Clearcell adenocarcinomas exhibiting scores $1+, 2+$, and $3+$ are shown in (a), (b), and (c), respectively. (a) Weak but definite cytoplasmic immunoreaction is noted, and membrane staining is discontinuous. (b) Continuous membrane immunoreaction with moderate intensity is noted. (c) Tumor cells show the strong membrane and cytoplasmic immunoreaction. Original magnification: $\times 400$.

detected in 16 clear-cell adenocarcinomas (18\%) and 3 non-clear-cell type ovarian carcinomas $(3 \%)$; all of the latter were serous adenocarcinomas $(3 \%, 3$ out of 86). True gene amplification of the MET gene 




Figure 2 Copy number status of the MET gene determined by brightfield double in situ hybridization in ovarian clear-cell adenocarcinomas. (a) A tumor defined as disomy. Most $(\geq 90 \%)$ of the tumor cells in this microphotograph show 1 to 2 dark brown (corresponding to the MET gene) and red (corresponding to CEN7) signals. (b) A tumor defined as low genomic gain. About half of the tumor cells in this microphotograph show three pairs of MET and CEN signals. (c) A tumor defined as high-level polysomy. Tumor cells show four to five pairs of MET and CEN7 signals. (d) A tumor defined as true gene amplification. In the focused tumor cell, MET signals form tight gene clusters, and a ratio of MET gene/CEN7 per cells is clearly $>2$. According to the described criteria, the tumors shown in (a, b) were defined to be double in situ hybridization negative and tumors in (c, d) were defined to be double in situ hybridization positive. Insets indicate the representative tumor cells in each microphotograph.

(Figure 2d) was observed in five cases with clear-cell adenocarcinoma (6\%), but none of the non-clear-cell type ovarian carcinomas. Consequently, double in situ hybridization-positive cases were more frequent in clear-cell adenocarcinomas than in non-clear-cell type ovarian carcinomas with a statistical significance (24 vs $3 \%, P<0.0001$ ), and also in the comparison between clear-cell adenocarcinomas and serous adenocarcinomas $(P=0.00011)$.

\section{Relationships Between MET Overexpression and Double In Situ Hybridization Positivity in Clear-Cell Adenocarcinomas}

Among the 20 clear-cell adenocarcinomas assigned as MET overexpression, 9 (45\%) and 11 (55\%) were double in situ hybridization positive and negative, respectively. Among the 70 clear-cell adenocarcinomas without MET overexpression, $12(17 \%)$ and 57 $(81 \%)$ were double in situ hybridization positive and negative, respectively. The remaining case was non-informative for double in situ hybridization analysis. Consequently, there was a significant correlation between MET overexpression and double in situ hybridization positivity $(P=0.0105)$.

\section{Clinicopathological Significance of MET Overexpression in Clear-Cell Adenocarcinomas}

The cases assigned as MET overexpression showed significantly shorter survival periods in comparison with the cases not assigned overexpression (5-year survival rates, $33.0 \%$ vs $75.7 \%, P=0.00012$ by logrank test) (Figure 3a). On the other hand, with regard to mean patient age, distribution of FIGO stage (stages I/II vs III/IV), presence of the residual tumor after initial surgery, frequency of lymph node metastasis, response to first-line chemotherapy of tumors, and the extent of histological differentiation of tumors (poorly differentiated tumors vs relatively 

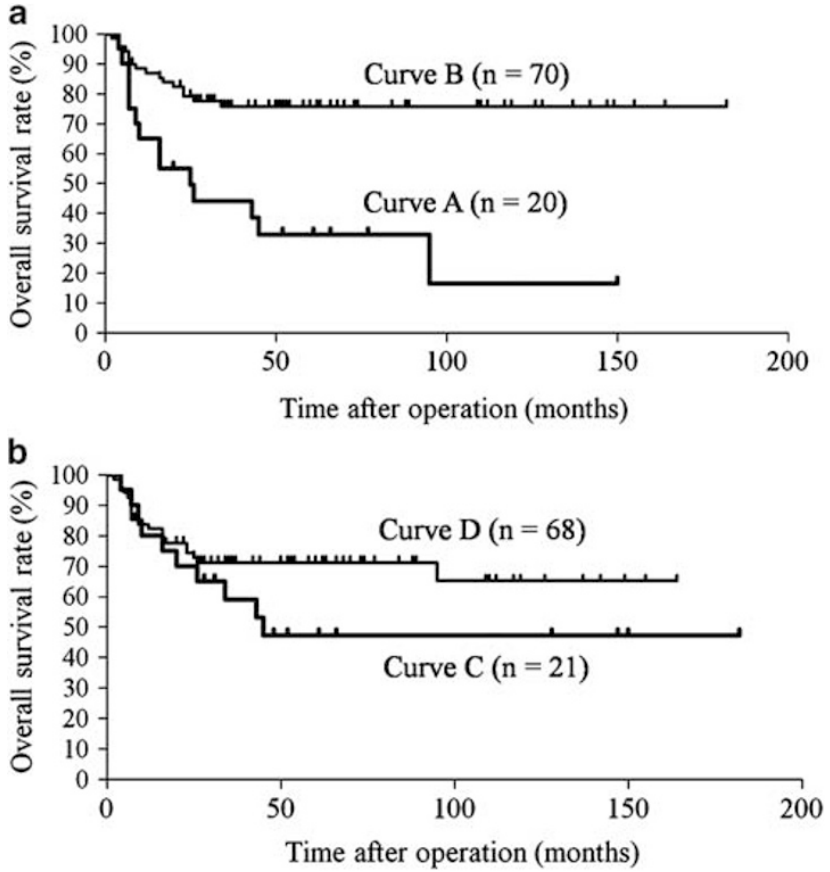

Figure 3 Overall survival curves for the patients with clear-cell adenocarcinoma, stratified by (a) MET overexpression detected by immunohistochemistry, and (b) positivity of double in situ hybridization for copy number alteration of the MET gene. (a) Curve A for the group with MET overexpression $(n=20)$, and curve B for the group without MET overexpression $(n=70)$. These two curves were significantly different $(P=0.00012$, by log-rank test). (b) Curve $\mathrm{C}$ for the double in situ hybridization-positive group $(n=21)$, and curve D for the double in situ hybridizationnegative group. Although the double in situ hybridizationpositive group shows a trend of shorter overall survival than the negative group, this difference is not statistically significant $(P=0.192$, by log-rank test $)$.

differentiated tumors), there were no significant differences between the two groups (Table 3).

In comparison with the double in situ hybridization-negative cases $(n=68)$, the double in situ hybridization-positive cases $(n=21)$ tended to be poorly differentiated histologically (52\% (11 of 21) Vs $15 \%$ (10 of 68$), P=0.00038$ ) (Table 3 ). On the other hand, there were no significant differences between the two groups with regard to mean patient age, distribution of FIGO stage (stages I/II vs III/IV), presence of the residual tumor after initial surgery, frequency of lymph node metastasis, and response to first-line chemotherapy of tumors (Table 3). Survival analyses showed that patients with double in situ hybridization-positive tumors tended to have a poorer outcome than those with double in situ hybridization-negative tumors (the 5-year survival rates were 47.3 and $71.1 \%$, respectively), but the difference was not statistically significant $(P=0.192$ by log-rank test) (Figure 3b).

A multivariate analysis using Cox's model identified that the presence of MET overexpression had an independent impact on overall survival $(P=0.0176$, relative risk $(R R)=2.42$ ) as well as advanced stages of disease $(P=0.0011, \mathrm{RR}=5.76)$ and a poorly differentiated histology of tumors $(P=0.00051$, $\mathrm{RR}=4.58$ ) (Table 4).

\section{Discussion}

In recent years, structural alteration of the MET gene, especially in the form of gene amplification, has received increased attention. Accumulated evidence suggests that MET can be an exciting and novel drug target, because of the success observed in vitro, in vivo, and in preclinical studies. Specifically, it has been shown that lung cancer and gastric cancer cell lines with MET gene amplification display significantly increased sensitivity to MET tyrosine kinase inhibitors, ${ }^{19,31,32}$ suggesting that patients with tumors containing amplified MET may have clinical responses to the MET inhibitors. Moreover, recent studies have demonstrated that $M E T$ amplification contributes to the acquired drug resistance to EGFR tyrosine kinase inhibitors, such as gefitinib and erlotinib, in non-small cell lung cancers. ${ }^{31}$ Additionally, in vitro, gefitinib sensitivity by cell lines can be restored by blocking MET signaling. ${ }^{31}$ These findings indicate that amplified MET could serve as a biomarker for targeted therapy, similar to HER2 gene amplification in breast cancer and EGFR gene mutation and/or amplification in lung cancer.

This study demonstrated that, among the ovarian carcinomas enrolled, overexpression of MET and the positivity of double in situ hybridization (high-level polysomy or true amplification of the MET) are highly characteristic for clear-cell adenocarcinoma: 22 and $24 \%$ in clear-cell adenocarcinomas compared with 0 and $3 \%$ in non-clear-cell type ovarian carcinomas, respectively. The frequency of MET overexpression shown in this study may be somewhat lower than the reported frequencies of MET expression in non-clear-cell type ovarian carcinomas, ${ }^{21-25}$ although weak immunoreaction (scored as $1+$ ) for MET was seen in 21\% of non-clear-cell type ovarian carcinomas enrolled in this study. These discrepancies would result from the criteria for evaluating the immunoreactions as well as the antibodies and the detection techniques used. However, we thought the criteria used in this study (the criteria was the same as that of the HercepTest ${ }^{\mathrm{TM}}$ for HER2/neu immunoreaction in breast cancer) were appropriate because the MET overexpression in clear-cell adenocarcinomas was highly correlated with patient's outcome being an independent prognostic factor for overall survival, probably reflecting true protein expression levels, and because MET overexpression defined was highly correlated with double in situ hybridization positivity. As well as the strong prognostic impact of MET overexpression in the patients with clear-cell adenocarcinoma, double in situ hybridization positivity was significantly correlated with the poorly differentiated histology of tumors. In the carcinomas of other 
Table 3 Correlation of MET overexpression and MET copy number alteration with clinicopathological parameters

\begin{tabular}{|c|c|c|c|c|c|c|}
\hline \multirow[t]{3}{*}{ Parameters } & \multicolumn{5}{|c|}{ Number of cases (\%) } & \multirow[t]{3}{*}{ P-value } \\
\hline & \multicolumn{2}{|c|}{$\begin{array}{c}\text { MET } \\
\text { overexpression }\end{array}$} & \multirow[t]{2}{*}{ P-value } & \multicolumn{2}{|c|}{$\begin{array}{c}\text { Double in situ } \\
\text { hybridization-positive }\end{array}$} & \\
\hline & Yes $(\mathrm{n}=20)$ & $N o(\mathrm{n}=70)$ & & Yes $(\mathrm{n}=21)$ & $N o(\mathrm{n}=68)$ & \\
\hline Age (years); median (s.d.) & $52.9(8.9)$ & $52.9(7.9)$ & 0.997 & $51.1(9.8)$ & $53.2(7.5)$ & 0.306 \\
\hline \multicolumn{7}{|l|}{ FIGO stage } \\
\hline I-II & $10(17)$ & $49(83)$ & $0.097^{\mathrm{a}}$ & $13(22)$ & $45(78)$ & $0.719^{\mathrm{a}}$ \\
\hline III-IV & $10(32)$ & $21(68)$ & & $8(26)$ & $23(74)$ & \\
\hline \multicolumn{7}{|l|}{ Residual tumor after initial surgery } \\
\hline Absent & $13(21)$ & $50(79)$ & 0.580 & $16(26)$ & $46(74)$ & 0.457 \\
\hline Present & $7(26)$ & $20(74)$ & & $5(19)$ & $22(81)$ & \\
\hline \multicolumn{7}{|l|}{ Response to chemotherapy } \\
\hline Complete or partial response $(n=10)$ & $1(10)$ & $9(90)$ & 0.148 & $1(10)$ & $9(90)$ & 0.382 \\
\hline $\begin{array}{l}\text { Stable disease or progressive } \\
\text { disease }(n=17)\end{array}$ & $6(35)$ & $11(65)$ & & $4(24)$ & $13(76)$ & \\
\hline \multicolumn{7}{|l|}{ Lymph node status } \\
\hline pNo & $8(17)$ & $38(83)$ & 0.953 & $11(24)$ & $34(76)$ & 0.968 \\
\hline pN1 & $2(17)$ & $10(83)$ & & $3(25)$ & $9(75)$ & \\
\hline pNx (not assessed) & 10 & 22 & & 7 & 25 & \\
\hline \multicolumn{7}{|l|}{ Tumor differentiation in histology } \\
\hline Relatively differentiated & 13 (19) & $55(81)$ & 0.213 & $10(15)$ & $58(85)$ & 0.0004 \\
\hline Poorly differentiated & $7(32)$ & $15(68)$ & & $11(52)$ & $10(48)$ & \\
\hline 5-Year survival (\%) & 33.0 & 75.7 & $0.00012^{b}$ & 47.3 & 71.1 & $0.192^{\mathrm{b}}$ \\
\hline
\end{tabular}

FIGO, International Federation of Gynaecology and Obstetrics; pNo, no lymph node metastases; pN1, one or more lymph node metastasis found in pelvic or paraaortic lymph nodes.

${ }^{\mathrm{a} C o m p a r i s o n}$ between stages I-II and stages III-IV tumors.

${ }^{\mathrm{b}}$ Calculated by log-rank test.

Bold values indicate statistical significance.

Table 4 Cox's proportional hazards model estimates of the significance of prognostic factors for patients with ovarian clear-cell adenocarcinoma

\begin{tabular}{|c|c|c|}
\hline Variables & P-value & $R R(95 \% C I)$ \\
\hline \multicolumn{3}{|l|}{ (a) Univariate Cox regression model } \\
\hline Age $(\geq 53 \text { years } v s<53 \text { years })^{a}$ & 0.014 & $0.35(0.15-0.81)$ \\
\hline FIGO stage (III-IV vs I-II) & $<0.0001$ & $7.76(3.49-17.25)$ \\
\hline Residual tumors (present vs absent) & $<0.0001$ & $5.99(2.86-12.58)$ \\
\hline Poorly differentiated tumor (present vs absent) & 0.0055 & $2.79(1.35-5.76)$ \\
\hline MET overexpression (yes vs no) & 0.0053 & $2.84(1.37-5.92)$ \\
\hline \multicolumn{3}{|l|}{ Double in situ hybridization for MET gene } \\
\hline (Positive vs negative) & 0.197 & $1.65(0.77-3.52)$ \\
\hline \multicolumn{3}{|l|}{ (b) Multivariate Cox regression model } \\
\hline Age $(\geq 53 \text { years } v s<53 \text { years })^{a}$ & 0.058 & $0.44(0.19-1.03)$ \\
\hline FIGO stage (III-IV vs I-II) & 0.0011 & $5.76(2.02-16.41)$ \\
\hline Residual tumors (present vs absent) & 0.055 & $2.51(0.98-6.42)$ \\
\hline Poorly differentiated tumor (present vs absent) & 0.00051 & $4.58(1.94-10.78)$ \\
\hline MET overexpression (yes vs no) & 0.018 & $2.42(1.17-5.03)$ \\
\hline
\end{tabular}

FIGO, International Federation of Gynaecology and Obstetrics; RR, relative risk; CI, confidence interval.

${ }^{\mathrm{a}}$ Mean values.

Bold values indicate a statistical significance.

primary sites, MET becomes increasingly overexpressed as the tumors become poorly differentiated, invasive, and metastatic. ${ }^{26,33}$ In vitro and in vivo MET receptor elicits a unique biological program leading to 'invasive growth,' resulting from the activation of proliferation, motility, cell dissociation, and protection from apoptosis. ${ }^{10,14}$ As shown in the uni- and multivariate analyses in this study, the 
poorly differentiated histology of tumors was found to be a significant prognostic factor for overall survival in the patients with clear-cell adenocarcinoma. Consequently, our present study suggests that, primarily by increased gene copy number (including true amplification), structural alteration of the MET gene causes MET protein overexpression and histological progression (dedifferentiation), and acts as an oncogene in the clear-cell adenocarcinoma.

Herein, with regard to the overexpression (or potentially activation) of MET receptor in clear-cell adenocarcinomas, we must discuss the possible mechanisms that may cause MET receptor activation other than gene amplification. Although a strong relationship between MET overexpression and double in situ hybridization positivity was statistically supported, more than half $(55 \%)$ of the clear-cell adenocarcinoma cases with MET overexpression were defined as double in situ hybridization negative, and $57 \%$ (12 of 21) of double in situ hybridization-positive cases were assigned as no or weak $(1+)$ immunoreaction for MET. These findings suggest that MET gene copy number alterations may potentiate but not always be required, or not be sufficient, for MET protein overexpression.

The absence of structural abnormality of the gene (ie double in situ hybridization-negativity defined in this study) in MET-overexpressing clear-cell adenocarcinomas suggests that the overexpression is secondary to the alteration of other signaling pathways. In addition to gene amplification, MET activation can occur through alternative mechanisms such as selected MET mutations, ligandindependent constitutive dimerization, pathway activation mediated by the hypoxia inducible factor (HIF1)- $\alpha$ under hypoxic conditions, transactivation by other receptors including EGFR, and loss of negative regulators such as the von Hippel-Lindau (VHL) tumor suppressor. ${ }^{8,9}$ Although somatic mutation of MET was not found in primary ovarian carcinomas, ${ }^{11,12}$ alternative expression of HIF1- $\alpha$, allelic losses on chromosome 3q25-q26 (containing VHL locus), and downregulation of VHL protein frequently occur in ovarian clear-cell adenocarcinoma. ${ }^{34-36}$ Moreover, Nam et $a l^{37}$ demonstrated that aberrant HGF/MET signaling induces centrosome amplification and chromosomal instability via the PI3K/Akt pathway. Among ovarian carcinomas, clear-cell adenocarcinoma is unique in that it has a high percentage $(46 \%)$ of PIK3CA-activating mutations. ${ }^{38}$ These mechanisms may either partially or completely eliminate the dependence of MET activation.

In summary, among ovarian carcinomas, MET overexpression and increased copy number (including true amplification) are highly characteristic and common events in clear-cell adenocarcinoma. MET acts as an oncoprotein in ovarian clear-cell adenocarcinoma, and its overexpression is highly correlated with prognosis of the patients with that carcinoma and associated with tumor progression/ dedifferentiation. These results contribute to the understanding of the pathogenesis of this highly lethal malignancy and support the development of targeted therapies that inhibit MET activation. As well as gene amplification, further studies are needed to evaluate the alternative MET activation mechanisms in clear-cell adenocarcinoma, including autocrine/paracrine loops of HGF-MET, hypoxia-related signaling pathways (ie HIF1- $\alpha$, VHL), dysregulated PI3K/AKT signaling pathway, and the potential of activating mutation of MET.

\section{Acknowledgements}

This work was supported in part by a grant-in-aid for cancer research from the Ministry of Health, Labor, and Welfare, Japan (HT). We are grateful to Eiko Munechika, MT, Roche Diagnostics, Tokyo, Japan, for technical assistance.

\section{Disclosure/conflict of interest}

The authors declare no conflict of interest.

\section{References}

1 Lee KR, Tavassoli FA, Part J, et al. Surface epithelialstromal tumours. In: Tavassoli FA, Devilee P (eds). World Health Organization Classification of Tumours. Pathology and Genetics of Tumours of the Breast and Female Genital Organs. IARC Press: Lyon, 2003. pp 117-145.

$2 \mathrm{Kaku} \mathrm{T}$, Ogawa S, Kawano Y, et al. Histological classification of ovarian cancer. Med Electron Microsc 2003;36:9-17.

3 Gynecologic cancer committee, Japan society of obstetrics and gynecology. Annual report of gynecological cancer patients in Japan 2006. Acta Obstet Gynecol Jpn 2008;60:1001-1085 (in Japanese).

4 Chan JK, Teoh D, Hu JM, et al. Do clear cell ovarian carcinomas have poorer prognosis compared to other epithelial cell types? A study of 1411 clear cell ovarian cancers. Gynecol Oncol 2008;109:370-376.

5 Mizuno M, Kikkawa F, Shibata K, et al. Long-term follow-up and prognostic factor analysis in clear cell adenocarcinoma of the ovary. J Surg Oncol 2006;94: 138-143.

6 O’Brien ME, Schofield JB, Tan S, et al. Clear cell epithelial ovarian cancer (mesonephroid): bad prognosis only in early stages. Gynecol Oncol 1993;49:250-254.

7 Takano M, Kikuchi Y, Yaegashi N, et al. Clear cell carcinoma of the ovary: a retrospective multicentre experience of 254 patients with complete surgical staging. Br J Cancer 2006;94:1369-1374.

8 Ma PC, Maulik G, Christensen J, et al. c-Met: structure, functions and potential for therapeutic inhibition. Cancer Metastasis Rev 2003;22:309-325.

9 Peruzzi B, Bottaro DP. Targeting the c-Met signaling pathway in cancer. Clin Cancer Res 2006;12:3657-3660.

10 Birchmeier C, Birchmeier W, Gherardi E, et al. Met, metastasis, motility and more. Nat Rev Mol Cell Biol 2003;4:915-925. 
11 Lorenzato A, Olivero M, Patanè S, et al. Novel somatic mutations of the MET oncogene in human carcinoma metastases activating cell motility and invasion. Cancer Res 2002;62:7025-7030.

12 Tanyi J, Tory K, Rigó Jr J, et al. Evaluation of the tyrosine kinase domain of the Met proto-oncogene in sporadic ovarian carcinomas. Pathol Oncol Res 1999; 5:187-191.

13 Schmidt L, Junker K, Nakaigawa N, et al. Novel mutations of the MET proto-oncogene in papillary renal carcinomas. Oncogene 1999;18:2343-2350.

14 Kuniyasu H, Yasui W, Kitadai Y, et al. Frequent amplification of the c-met gene in scirrhous type stomach cancer. Biochem Biophys Res Commun 1992;189:227-232.

15 Tsujimoto H, Sugihara H, Hagiwara A, et al. Amplification of growth factor receptor genes and DNA ploidy pattern in the progression of gastric cancer. Virchows Arch 1997;431:383-389.

16 Hara T, Ooi A, Kobayashi M, et al. Amplification of cmyc, K-sam, and c-met in gastric cancers: detection by fluorescence in situ hybridization. Lab Invest 1998;78:1143-1153.

17 Miller CT, Lin L, Casper AM, et al. Genomic amplification of MET with boundaries within fragile site FRA7G and upregulation of MET pathways in esophageal adenocarcinoma. Oncogene 2006;25:409-418.

18 Zhao X, Weir BA, LaFramboise T, et al. Homozygous deletions and chromosome amplifications in human lung carcinomas revealed by single nucleotide polymorphism array analysis. Cancer Res 2005;65: 5561-5570.

19 Bean J, Brennan C, Shih JY, et al. MET amplification occurs with or without T790M mutations in EGFR mutant lung tumors with acquired resistance to gefitinib or erlotinib. Proc Natl Acad Sci USA 2007; 104:20932-20937.

20 Di Renzo MF, Olivero M, Giacomini A, et al. Overexpression and amplification of the met/HGF receptor gene during the progression of colorectal cancer. Clin Cancer Res 1995;1:147-154.

$21 \mathrm{Di}$ Renzo MF, Narsimhan RP, Olivero $\mathrm{M}$, et al. Expression of the Met/HGF receptor in normal and neoplastic human tissues. Oncogene 1991;6: 1997-2003.

22 Huntsman D, Resau JH, Klineberg E, et al. Comparison of c-met expression in ovarian epithelial tumors and normal epithelia of the female reproductive tract by quantitative laser scan microscopy. Am J Pathol 1999;155:343-348.

23 Wong AS, Roskelley CD, Pelech S, et al. Progressive changes in Met-dependent signaling in a human ovarian surface epithelial model of malignant transformation. Exp Cell Res 2004;299:248-256.

24 Ayhan A, Ertunc D, Tok EC, et al. Expression of the cMet in advanced epithelial ovarian cancer and its prognostic significance. Int $\mathrm{J}$ Gynecol Cancer 2005;15:618-623.

25 Sawada K, Radjabi AR, Shinomiya N, et al. c-Met overexpression is a prognostic factor in ovarian cancer and an effective target for inhibition of peritoneal dissemination and invasion. Cancer Res 2007;67: 1670-1679.
26 Zhou HY, Pon YL, Wong AST. HGF/MET signaling in ovarian cancer. Curr Mol Med 2008;8:469-480.

27 Therasse P, Arbuck SG, Eisenhauer EA, et al. New guidelines to evaluate the response to treatment in solid tumors. European Organization for Research and Treatment of Cancer, National Cancer Institute of the United States, National Cancer Institute of Canada. J Natl Cancer Inst 2000;92:205-216.

28 Nitta H, Hauss-Wegrzyniak B, Lehrkamp M, et al. Development of automated brightfield double in situ hybridization (BDISH) application for HER2 gene and chromosome 17 centromere (CEN 17) for breast carcinomas and an assay performance comparison to manual dual color HER2 fluorescence in situ hybridization (FISH). Diagn Pathol 2008;3:41.

29 Pauletti G, Dandekar S, Rong H, et al. Assessment of methods for tissue-based detection of the HER-2/neu alteration in human breast cancer: a direct comparison of fluorescence in situ hybridization and immunohistochemistry. J Clin Oncol 2000;18:3651-3664.

30 Cappuzzo F, Hirsch FR, Rossi E, et al. Epidermal growth factor receptor gene and protein and gefitinib sensitivity in non-small-cell lung cancer. J Natl Cancer Inst 2005;97:643-655.

31 Engelman JA, Zejnullahu K, Mitsudomi T, et al. MET amplification leads to gefitinib resistance in lung cancer by activating ERBB3 signaling. Science 2007;316:1039-1043.

32 Smolen GA, Sordella R, Muir B, et al. Amplification of MET may identify a subset of cancers with extreme sensitivity to the selective tyrosine kinase inhibitor PHA-665752. Proc Natl Acad Sci USA 2006;103: 2316-2321.

33 Beviglia L, Matsumoto K, Lin CS, et al. Expression of the c-Met/HGF receptor in human breast carcinoma: correlation with tumor progression. Int J Cancer 1997; 74:301-309.

34 Osada R, Horiuchi A, Kikuchi N, et al. Expression of hypoxia-inducible factor 1alpha, hypoxia-inducible factor 2alpha, and von Hippel-Lindau protein in epithelial ovarian neoplasms and allelic loss of von Hippel-Lindau gene: nuclear expression of hypoxiainducible factor 1alpha is an independent prognostic factor in ovarian carcinoma. Hum Pathol 2007;38: 1310-1320.

35 Yasuda M, Miyazawa M, Fujita M, et al. Expression of hypoxia inducible factor-1alpha (HIF-1alpha) and glucose transporter-1 (GLUT-1) in ovarian adenocarcinomas: difference in hypoxic status depending on histological character. Oncol Rep 2008;19:111-116.

36 Yamamoto S, Tsuda $\mathrm{H}$, Suzuki $\mathrm{K}$, et al. An allelotype analysis indicating the presence of two distinct ovarian clear-cell carcinogenic pathways: endometriosis-associated pathway vs clear-cell adenofibroma-associated pathway. Virchows Arch 2009;455: 261-270.

37 Nam HJ, Chae S, Jang SH, et al. The PI3K-Akt mediates oncogenic Met-induced centrosome amplification and chromosome instability. Carcinogenesis 2010;31: 1531-1540.

38 Kuo KT, Mao TL, Jones S, et al. Frequent activating mutations of PIK3CA in ovarian clear cell carcinoma. Am J Pathol 2009;174:1597-1601. 